\section{Dementia \\ and Geriatric}

Cognitive Disorders
Dement Geriatr Cogn Disord 2017;43:320-329

This article is licensed under the Creative Commons Attribution-NonCommercial-NoDerivatives 4.0 International License (CC BY-NC-ND) (http://www.karger.com/Services/OpenAccessLicense). Usage and distribu-

tion for commercial purposes as well as any distribution of modified material requires written permission.

\title{
The Determinants of Quality of Life of Nursing Home Residents with Young-Onset Dementia and the Differences between Dementia Subtypes
}

\author{
Britt Appelhof ${ }^{a-c} \quad$ Christian Bakker ${ }^{a, c, d}$ \\ Jeannette C.L. Van Duinen-van den Ijssel ${ }^{a}{ }^{c}$ Sandra A. Zwijsen ${ }^{e}$ \\ Martin Smalbrugge ${ }^{e} \quad$ Frans R.J. Verhey ${ }^{f}$ Marjolein E. de Vugt ${ }^{f}$ \\ Sytse U. Zuidemag Raymond T.C.M. Koopmans ${ }^{a, c, h}$ \\ ${ }^{a}$ Center for Family Medicine, Geriatric Care and Public Health, Department of Primary and

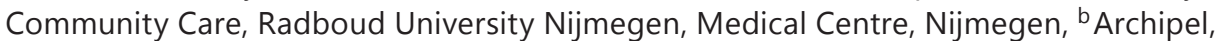 \\ Landrijt, Knowledge Center for Specialized Care, Eindhoven, ' Radboud Alzheimer Center, \\ Nijmegen, dFlorence, Mariahoeve, Center for Specialized Care in Young-Onset Dementia, \\ The Hague, ${ }^{e}$ Department of General Practice and Elderly Care Medicine/EMGO + Institute \\ for Health and Care Research, VU Medical Centre, Amsterdam, ${ }^{f}$ Alzheimer Center \\ Limburg, School for Mental Health and Neuroscience, Maastricht University Medical \\ Center, Maastricht, ${ }^{9}$ Department of General Practice, University of Groningen, University \\ Medical Center Groningen, Groningen, and h De Waalboog "Joachim en Anna," Center for \\ Specialized Geriatric Care, Nijmegen, The Netherlands
}

\section{Keywords}

Young-onset dementia - Quality of life · Nursing home $\cdot$ Neuropsychiatric symptoms .

Psychotropic drugs

\begin{abstract}
Aims: The aims of this study are to (1) explore the determinants of quality of life (QoL) in nursing home residents with young-onset dementia (YOD), (2) investigate whether there are differences between dementia subtypes (Alzheimer dementia, vascular/mixed dementia, frontotemporal dementia, other) regarding these determinants, and (3) compare QoL profiles of YOD nursing home residents across dementia subtypes. Methods: This cross-sectional study included 207 nursing home residents. Multilevel modeling was used to determine the relationships between QoL and neuropsychiatric symptoms (NPS), dementia severity, psychotropic drug use (PDU), dementia subtype, age, and gender. Additional multilevel models were used to compare aspects of QoL between dementia subtypes. Results: Residents' QoL was negatively associated with advanced dementia, PDU, and NPS. In general, the relationships between the determinants and QoL were similar across the dementia subtypes. Aspects of
\end{abstract}


QoL differed by dementia subtype. Residents with frontotemporal dementia showed less negative emotions, accepted more help and experienced better quality of relationships with professional caregivers, had a more positive self-image, felt more comfortable in the nursing home environment, and experienced lower quality of social relationships. Conclusions: Considering the high rates of NPS and PDU in YOD residents and their negative associations with QoL, we recommend emphasizing services to manage and reduce NPS and PDU in nursing home residents with YOD. Furthermore, our findings suggest accounting for differences in aspects of QoL by dementia subtype to address specific needs and thereby improve QoL.

(C) 2017 The Author(s)

Published by S. Karger AG, Basel

\section{Introduction}

Quality of life (QoL) is increasingly recognized as an important measure of general wellbeing in dementia [1]. Therefore, in the past decade, several studies have investigated the factors that influence QoL in people with dementia. Better QoL has been associated with a reduced awareness of people's own cognitive deficits and better mental health of the caregiver in community-dwelling people with dementia [2,3]. Additionally, the subtype of dementia might be associated with QoL. For instance, Thomas et al. [3] and Bostrom et al. [4] found a significant lower QoL in community-dwelling people with Lewy body dementia compared to Alzheimer dementia (AD). Furthermore, increased cognitive impairment and the presence of neuropsychiatric symptoms (NPS) were negatively associated with QoL in both community-dwelling people and nursing home residents with dementia [2, 3, 5-13]. Of the NPS studied, especially depression was strongly associated with lower QoL scores [5, 7-11,14-16]. In addition, apathy, psychosis, and agitation are negatively associated with QoL $[7,10,17]$. Moreover, NPS are often treated with psychotropic drugs, some of which have also been associated with poor health outcomes and reduced QoL in nursing home residents with dementia $[5,7,18]$.

The current knowledge on the determinants of QoL in dementia is largely based on research with people with late-onset dementia (LOD). People with young-onset dementia (YOD), defined as dementia with an onset of symptoms before the age of 65 years, often encounter specific challenges such as a substantial delay in diagnosis, loss of employment, financial issues, social isolation, changes in relationships, and lack of meaningful daytime activities, all adding to the negative impact on QoL [19-22]. Indeed, current research suggests that younger age is associated with a worse QoL in LOD [9]. Furthermore, NPS are very common in nursing home residents with YOD. A recent Dutch study showed that $90 \%$ of nursing home residents with YOD showed one or more NPS [23, 24]. Of the residents, $87 \%$ used one or more psychotropic drug(s) [23]. These prevalence rates of NPS and psychotropic drug use (PDU) seem even higher than in LOD $[23,24]$, placing younger nursing home residents with dementia at particular risk of experiencing poor QoL.

Research on the determinants of QoL in YOD is scarce. One Dutch study found that lower levels of QoL in community-dwelling people with YOD were associated with high levels of depression [25]. In that study, no association was found between QoL and other NPS or dementia severity. A recent review noted that the studies on QoL in YOD are heterogeneous in terms of the included dementia subtypes, which may have a negative impact on the consistency of the results [26]. The authors suggest that studies should include homogeneous samples to improve the understanding of the determinants of QoL in YOD. Moreover, in current research on YOD, unclear definitions of the concept of QoL are used, and therefore it is uncertain which specific aspects of QoL were measured [26]. The multidimensionality of the QoL construct stresses the importance of investigating QoL domains separately to provide 
Appelhof et al.: The Determinants of Quality of Life of Nursing Home Residents with

Young-Onset Dementia and the Differences between Dementia Subtypes

clarity regarding the possible differences in specific QoL domains and thereby prevent a loss of information [27-29].

A better understanding of these determinants in YOD and the possible differences in QoL across dementia subtypes can improve the care of YOD nursing home residents. Therefore, the aims of the current study are to (1) explore the determinants (NPS, PDU, dementia subtype, dementia severity, age, gender) of QoL in YOD nursing home residents, (2) investigate whether there are differences between dementia subtypes regarding the determinants of QoL, and (3) compare the QoL domains of residents across the three most common YOD subtypes.

\section{Materials and Methods}

Study Design and Selection of Participants

In this cross-sectional study, baseline data from a larger multicenter study aimed at the improvement of the management of challenging behavior in YOD, the Behavior and Evolution of Young-ONset Dementia part 2 (BEYOND-II) study, were used. Thirteen YOD special care units (SCUs) were recruited through nursing homes that are affiliated with the Dutch YOD Knowledge Center (DKC). Residents with a dementia diagnosis with a symptom onset before the age of 65 who resided on the SCU for at least 1 month were eligible for inclusion in the study. The exclusion criteria were lack of informed consent, dementia caused by human immunodeficiency virus, traumatic brain injury, Down syndrome, Korsakov syndrome, or Huntington disease. The dementia diagnosis was established according to the 4th edition of the Diagnostic and Statistical Manual of Mental Disorders, Text Revision 2000, and international accepted criteria for diagnosing dementia subtypes were used and were retrieved from medical files [30-35].

The study protocol was approved by the Medical Ethics Committee region Arnhem/Nijmegen (file number 2015-1558) and registered in the Dutch Trial Register (Trial ID NTR5018). This research project was conducted according to the principles of the Declaration of Helsinki (version November 2013, www.wma. net) and in agreement with the laws regarding medical-scientific research in humans (WMO).

\section{Data Collection and Assessments}

Information on inclusion and exclusion criteria was sent to the participating SCUs for the initial selection of residents eligible for the study. The legal representatives of the residents who met inclusion criteria were asked for written informed consent. All data were anonymized. Trained researchers and research assistants collected the data through structured interviews with the nursing staff and from the resident's medical files. Regular consensus meetings with the research team ensured the integrity of the data collection process.

Quality of Life

QoL was assessed with the Quality of Life in Dementia (QUALIDEM) questionnaire. The QUALIDEM is an observational instrument, and the reliability and validity are satisfactory $[11,27]$. The scale includes 37 items describing observable behavior with four possible responses to how often this behavior has been observed in the past week, ranging from never to almost daily. The QUALIDEM consists of nine subscales: Care relationship (ranging from 0 to 21), Positive affect (ranging from 0 to 18), Negative affect (ranging from 0 to 9), Restless tense behavior (ranging from 0 to 9), Positive self-image (ranging from 0 to 9), Social relations (ranging from 0 to 18), Social isolation (ranging from 0 to 9), Feeling at home (ranging from 0 to 12), and Having something to do (ranging from 0 to 6). A total score is calculated by summing the scores of the nine subscales (ranging from 0 to 111). Higher (sub)scale scores indicate a higher QoL.

\section{Other Resident Characteristics}

NPS were assessed using the Dutch version of the Neuropsychiatric Inventory-nursing home version (NPI-NH). The NPI-NH has a high-interrater reliability and has been found to be a valid instrument for the assessment of a wide range of NPS in dementia [36,37]. For each symptom, the frequency and severity are rated on a 4-point (ranging from 1 to 4 ) and 3-point scale (ranging from 1 to 3 ). We used NPI-NH factor scores based on a previous study in which five NPI-NH factors in a large nursing home sample were found: (1) agitation/aggression, (2) depression, (3) psychosis, (4) psychomotor agitation, and (5) apathy [38]. 
Dementia

Cognitive Disorders

\begin{tabular}{l|l}
\hline Dement Geriatr Cogn Disord 2017;43:320-329 \\
\hline DOI: 10.1159/000477087 & $\begin{array}{l}\text { C 2017 S. Karger AG, Basel } \\
\text { www.karger.com/dem }\end{array}$ \\
\hline
\end{tabular}

Appelhof et al.: The Determinants of Quality of Life of Nursing Home Residents with Young-Onset Dementia and the Differences between Dementia Subtypes

Dementia severity was assessed with the Global Deterioration rating Scale (GDS) [39]. The GDS is a validated scale that describes seven different stages of dementia ranging from "subjectively and objectively normal cognition" to "severe cognitive decline." The GDS has been validated against behavioral, neuroanatomic and neurophysiologic measures [39].

PDU was derived from the nursing homes pharmacists' electronic files and was classified according to the Anatomical Therapeutic Chemical (ATC) classification system into antipsychotics, anxiolytics, hypnotics, antidepressants, antiepileptics, antidementia drugs, and any psychotropic medication [40]. Medical and demographic data were extracted from the resident's medical files. Data on the dementia subtype, age, gender, length of stay at the SCU, and date of inclusion were recorded.

\section{Statistical Analysis}

Analyses were performed using the Statistical Package for the Social Sciences (SPSS) version 22. Demographic variables (age, gender, length of stay at the SCU, dementia subtype) were described by calculating means or proportions. Multilevel modeling (random intercept linear mixed model) was used to determine the relationship between the total QUALIDEM (QoL) score as the dependent variable and age, gender, dementia severity (GDS: mild, moderate, severe), dementia subtype (AD, vascular/mixed, frontotemporal dementia [FTD], other consisting of Lewy body dementia, Parkinson dementia, alcohol-related dementia, neurosyphilis, and dementia not otherwise specified), the five separate NPI-NH factor scores (summed FxS symptom scores) and PDU (using dichotomous categories: present or absent) as the independent variables. The multilevel model corrected for the clustering of residents in the 13 different SCUs. The explained variance at the resident level was calculated [41]. To investigate the effects of dementia subtype on the relationships between QoL total score and the determinants age, gender, dementia severity (GDS: mild, moderate, severe), five NPI-NH factor scores (summed FxS symptom scores), and PDU (present or absent), the interaction terms of dementia subtype with these determinants were added to the model.

Furthermore, the estimated marginal means of the QUALIDEM subscale scores were calculated for the dementia subtypes: Alzheimer, vascular/mixed, and frontotemporal. To compare the estimated means, additional multilevel models were used with the QUALIDEM subscale scores as the dependent variables and dementia severity, age, and gender as the independent variables. In all analyses, a two-tailed $p$ value $<0.05$ was considered statistically significant.

\section{Results}

\section{Resident Characteristics}

A total of 207 residents were included. Mean age was 64 years (SD =6.1), and the male to female ratio was approximately equal (Table 1). The majority (61.4\%) had severe dementia, and most residents were diagnosed with AD (46.4\%). The residents had a mean QoL total score of 76.6 (SD = 16.0) and a mean NPS total score of 24.1 (SD = 19.7). Approximately $68 \%$ used at least one psychotropic drug.

\section{Determinants of QoL}

A multilevel model showed that a low QoL was associated with advanced dementia, PDU, and the neuropsychiatric factors agitation/aggression, depression, and apathy (Table 2). These variables together accounted for $44 \%$ of the variance in total QoL score on the resident level.

Furthermore, after adding the interaction terms to the model, a significant interaction effect between dementia subtype and the factor psychomotor agitation $(p=0.046)$ was found. The relationship between the factor psychomotor agitation and QoL differed between the AD and the FTD groups. Residents with AD who showed high scores on the psychomotor agitation factor experienced a higher QoL $(B=0.240)$, whereas residents with FTD showing high scores on the psychomotor agitation factor experienced a lower QoL $(B=-0.678)$. No other significant interaction effects were found. 
Table 2. Multilevel model with significant correlates of QoL

\begin{tabular}{|c|c|c|c|c|c|}
\hline & \multirow[t]{2}{*}{ B } & \multirow[t]{2}{*}{ Se B } & \multirow[t]{2}{*}{$p$} & \multicolumn{2}{|l|}{$95 \% \mathrm{CI}$} \\
\hline & & & & lower bound & upper bound \\
\hline Gender (ref. female) & -2.27 & 1.883 & 0.229 & -5.985 & 1.443 \\
\hline Age & 0.240 & 0.152 & 0.099 & -0.059 & 0.539 \\
\hline PDU (ref. none PDU) & -4.863 & -1.884 & $0.011^{*}$ & -8.581 & -1.145 \\
\hline Dementia subtype (ref. AD) & & & 0.231 & & \\
\hline Other & -0.780 & 2.925 & 0.790 & -6.550 & 4.990 \\
\hline Vasc./mixed & -3.280 & 2.699 & 0.226 & -8.600 & 2.048 \\
\hline FTD & 2.699 & 2.296 & 0.241 & -1.830 & 7.228 \\
\hline $\mathrm{AD}$ & 0 & & & & \\
\hline Dementia severity (ref. severe) & & & $0.005^{*}$ & & \\
\hline Mild $(3,4)$ & 7.410 & 2.539 & 0.004 & 2.400 & 12.420 \\
\hline Moderate (5) & 5.070 & 2.255 & 0.026 & 0.618 & 9.515 \\
\hline Severe $(6,7)$ & 0 & & & & \\
\hline NPI factor agitation & -0.528 & 0.111 & $0.000^{* *}$ & -0.745 & -0.312 \\
\hline NPI factor depression & -0.670 & 0.204 & $0.001^{* *}$ & -1.071 & -0.265 \\
\hline NPI factor psychosis & -0.181 & 0.242 & 0.455 & -0.659 & 0.296 \\
\hline NPI factor psychomotor agitation & 0.042 & 0.159 & 0.793 & -0.272 & 0.356 \\
\hline NPI factor apathy & -0.711 & 0.149 & $0.000^{* *}$ & -1.006 & -0.416 \\
\hline
\end{tabular}

QoL, quality of life, QUALIDEM total score; PDU, psychotropic drug use; AD, Alzheimer dementia; vasc./ mixed, vascular/mixed dementia; FTD, frontotemporal dementia; NPI-NH, Neuropsychiatric Inventory. ${ }^{*} p<$ $0.05 ; * *<0.01$. Level-one explained proportion of variance $=0.430$.

Table 3. Differences in QoL between Alzheimer, vascular/mixed, and frontotemporal dementia groups

\begin{tabular}{lrrrl}
\hline & $\begin{array}{l}\text { AD } \\
(n=96)\end{array}$ & $\begin{array}{l}\text { Vasc./mixed } \\
(n=28)\end{array}$ & $\begin{array}{l}\text { FTD } \\
(n=62)\end{array}$ & $p$ \\
\hline QUALIDEM subscale scores (estimated mean) $^{\mathrm{a}}$ & & & & \\
Care relationship & 14.41 & 13.26 & 16.02 & $0.030^{*}$ \\
Positive affect & 14.53 & 13.71 & 12.97 & 0.162 \\
Negative affect & 5.75 & 6.50 & 7.02 & $0.023^{*}$ \\
Restless tense behavior & 5.23 & 5.61 & 5.82 & 0.505 \\
Positive self-image & 7.87 & 7.45 & 8.49 & $0.029^{*}$ \\
Social relations & 11.71 & 12.16 & 9.77 & $0.006^{* *}$ \\
Social isolation & 6.91 & 6.57 & 6.90 & 0.771 \\
Feeling at home & 9.78 & 8.67 & 10.04 & $0.039^{*}$ \\
Something to do & 3.12 & 3.78 & 2.97 & 0.140 \\
\hline
\end{tabular}

QoL, quality of life; AD, Alzheimer dementia; vasc./mixed, vascular/mixed dementia; FTD, frontotemporal dementia. All outcome variables are adjusted for age, gender, and dementia severity. ${ }^{*} p<0.05$; ${ }^{* *} p<0.01$. ${ }^{a}$ Higher subscale scores indicate higher QoL.

home" was higher in residents with FTD than in residents with vasc./mixed dementia (mean 10.04 vs. 8.67, $p=0.014$ ). Finally, residents with FTD scored lower on the subscale "Social relations" than residents with $\mathrm{AD}$ (mean 9.77 vs. $11.71, p=0.005$ ) and with vasc./mixed dementia (mean 9.77 vs. $12.16, p=0.007$ ). 
Appelhof et al.: The Determinants of Quality of Life of Nursing Home Residents with Young-Onset Dementia and the Differences between Dementia Subtypes

\section{Discussion}

In this study, we found that the residents' QoL was negatively associated with advanced dementia, PDU, and the factors agitation/aggression, depression, and apathy. The model showed that all the variables included accounted for $44 \%$ of the variance in the total QoL score. The relationship between QoL and the determinants studied did not differ for dementia subtypes, with the exception of the factor psychomotor agitation. Although no association was found between overall QoL and dementia subtype, we did find differences between residents with AD, vasc./mixed dementia and FTD regarding the separate QoL domains.

Our findings suggest that the same determinants of QoL in LOD also apply to YOD nursing home residents. Advanced dementia was found associated with poor QoL in nursing home residents with LOD [12]. Also, similar to our findings, PDU, agitation, and depression have been found negatively associated with QoL in LOD [7]. Furthermore, in LOD, a relationship between poorer QoL and high levels of apathy was found [8]. Therefore, this might suggest that the high rates of NPS and PDU found in residents with YOD indeed place younger residents with dementia in particular at risk of experiencing poor QoL [23, 24].

Furthermore, residents with FTD scored better on four QoL domains. This might appear counterintuitive because of the higher levels of agitation, apathy, disinhibition, and irritability found in FTD [42, 43]. An explanation for this finding could be that FTD is characterized by an early loss of disease awareness, which has been found to be associated with the occurrence of fewer depressive symptoms and might also have a positive influence on self-image $[44,45]$. Our findings are also consistent with a recent study on community-dwelling people with YOD, which indicated that people with FTD rated their own QoL higher than other subtypes of dementia [25]. Therefore, people with FTD might communicate less problems and negative emotions towards health-care professionals influencing reliability of proxy reports of their QoL. Furthermore, institutionalization provides a structured environment, which might have a particular advantage for people with FTD because of the higher levels of apathy found in FTD [42]. We also found that residents with FTD appeared to experience a lower quality of social relationships. This finding could be explained by the higher levels of agitation, apathy, disinhibition, and irritability found in residents with FTD [42, 43], as these characteristics might invoke negative reactions from other residents, hinder social interactions, and therefore result in poorer quality of social relationships.

Several limitations of this study should be considered. We used the total score on the QUALIDEM to reduce the number of tests and therefore diminish the risk of a Type 1 error. The use of the QUALIDEM total score also enabled a comparison of our results with those of other studies on the determinants of QoL in LOD using a similar methodology. However, we should be aware that using this total score might have resulted in a loss of information by not taking into account the multidimensionality of the construct of QoL. Another inevitable limitation of this study was the use of proxy reports to investigate residents' QoL. Dröes et al. [28] found that there were differences in the perspectives on QoL between people with dementia and their caregivers. Also, the younger age of our residents could have influenced the proxy reports. Nurses might be more inclined to observe a lower QoL in YOD, because dementia is considered a disease of old age. Having this disease at a younger age might be considered to have a more negative influence on well-being. However, most residents in this study had advanced dementia. Even when sufficient communicative abilities were present, their severe cognitive impairments likely would have threatened the validity of self-reported results. Nonetheless, we should be aware that the QoL ratings could have been influenced by the professional caregivers' attitudes towards the resident and dementia $[10,12,16]$. Furthermore, we should be aware that correlations between the QUALIDEM subscales and NPI factors could have influenced the explained variance to some degree. Also, other factors possibly 
Appelhof et al.: The Determinants of Quality of Life of Nursing Home Residents with Young-Onset Dementia and the Differences between Dementia Subtypes

contributing to the QoL of residents with YOD (e.g., nursing home environment, physical impairments, pain, frequency of visits from family members) have not been studied. Additionally, the residents in this study were only recruited from nursing homes which were affiliated with the Dutch YOD Knowledge Center. Therefore, selection bias might have taken place possibly influencing the external validity of our findings. Finally, some caution should be used when interpreting the findings of the subgroup analyses investigating the interaction effects and the multilevel models with QUALIDEM subscale scores as the dependent variables. Considering the large number of tests in the analyses, there was a risk of type 1 error in these subgroup analyses; this might have been reflected in the differences observed in the effects of psychomotor agitation on QoL between dementia subtypes, as there is no apparent explanation for this finding. Also, vascular dementia and mixed dementia were combined in order to gain statistical power. However, as those dementia subtypes might differ in phenomenology, this could have partly influenced the results. Further testing in future studies including larger groups of less common diagnoses is necessary to confirm the differences in the determinants of QoL and QoL profiles between dementia subtypes found in our exploratory analyses.

This study provides important insight into the determinants of QoL in nursing home residents with YOD. The high rates of NPS and PDU in nursing home residents with YOD [23] raise concern given the strong associations found in this study between these variables and QoL. Furthermore, our results challenge the existing pharmacological interventions in the treatment of NPS, as PDU by itself also is negatively associated with QoL in YOD. This finding is in line with other studies on QoL in LOD $[7,5,18]$. Therefore, in the treatment of NPS, the well-being of nursing home residents with YOD will probably benefit most from nonpharmacological interventions specifically aimed at reducing agitation/aggression, depression, and apathy. More research is needed on the influence of PDU on QoL in YOD taking into account the specific categories of psychotropic medication as well as duration, usage, dose, and causality.

Additionally, our results suggest that nursing home residents with AD and vasc./mixed dementia might benefit more from interventions to prevent or diminish the risk of experiencing negative emotions (e.g., supporting conversations with a health-care professional, regular check for depressive symptoms, avoid confrontation with their inabilities). On the other hand, in order to improve their quality of social relationships, nursing home residents with FTD might benefit from interventions aimed at increasing positive social interaction for instance with family, other nursing home residents or volunteers. Health-care professionals should receive education to raise their awareness about the possible differences between dementia subtypes regarding aspects of QoL and therewith ensure that they will provide care that meets the specific care needs of all diagnostic groups in order to improve residents' QoL.

\section{Acknowledgement}

We thank Mandy Wijnen and Yvette Daniels for collecting the data and Hans Bor for his support with performing the analyses. Additionally, we are grateful for the cooperation of the staff of the participating nursing homes.

This study was funded by the Netherlands Organization for Health Research and Development (ZonMW, No. 733050402), the Archipel Care Group in the Netherlands, the Florence Care Group in the Netherlands, the Dutch YOD Knowledge Center, and the Dutch Alzheimer Society.

\section{Disclosure Statement}

All authors declare no conflicts of interest. 
Appelhof et al.: The Determinants of Quality of Life of Nursing Home Residents with

Young-Onset Dementia and the Differences between Dementia Subtypes

\section{References}

1 Ettema TP, Droes RM, de Lange J, Mellenberg GJ, Ribbe MW: A review of quality of life instruments used in dementia. Qual Life Res 2005;14:675-686.

2 Hurt CS, Banerjee S, Tunnard C, Whitehead DL, Tsolaki M, Mecocci P, Kloszewska I, Soininen H, Vellas B, Lovestone S: Insight, cognition and quality of life in Alzheimer's disease. J Neurol Neurosurg Psychiatry 2010;81: 331-336.

3 Thomas P, Lalloue F, Preux PM, Hazif-Thomas C, Pariel S, Inscale R, Belhim J, Clement JP: Dementia patients caregivers quality of life: the PIXEL study. Int J Geriatr Psychiatry 2006;21:50-56.

4 Bostrom F, Jonsson L, Minthon L, Londos E: Patients with dementia with Lewy bodies have more impaired quality of life than patients with Alzheimer disease. Alzheimer Dis Assoc Disord 2007;21:150-154.

5 Gonzalez-Salvador T, Lyketsos CG, Baker A, Hovanec I, Roques C, Brandt J, Steele C: Quality of life in dementia patients in long-term care. Int J Geriatr Psychiatry 2000;15:181-189.

6 Sloane PD, Zimmerman S, Williams CS, Reed PS, Karminder SG, Preisser JS: Evaluating the quality of life of long-term care residents with dementia. Gerontologist 2005;45:37-49.

7 Wetzels R, Zuidema S, de Jonghe J, Verhey F, Koopmans R: Determinants of quality of life in nursing home residents with dementia. Dement Geriatr Cogn Disord 2010;29:189-197.

8 Samus QM, Rosenblatt A, Steele C, Baker A, Harper M, Brandt J, Mayer L, Rabins PV, Lyketsos CG: The association of neuropsychiatric symptoms and environment with quality of life in assisted living residents with dementia. Gerontologist 2005;45:19-26.

9 Banerjee S, Smith SC, Lamping DL, Harwoord RH, Foley B, Smith P, Murray J, Prince M, Levin E, Mann A, Knapp M: Quality of life in dementia: more than just cognition: an analysis of associations with quality of life in dementia. J Neurol Neurosurg Psychiatry 2006;77:146-148.

10 Hoe J, Hancock G, Livingston G, Orrell M: Quality of life of people with dementia in residential care homes. Br J Psychiatry 2006;188:460-464.

11 Ettema TP, Droes RM, de Lange J, Mellenberg GJ, Ribbe MW: QUALIDEM: development and evaluation of a dementia specific quality of life instrument-validation. Int J Geriatr Psychiatry 2007;22:424-430.

12 Winzelberg GS, Williams CS, Preisser JS, Zimmerman S, Sloana PD: Factors associated with nursing assistant quality-of-life ratings for residents with dementia in long-term care facilities. Gerontologist 2005;45:106114.

13 Hurt C, Bhattacharyya S, Burns A, Camus V, Liperoti R, Marriott A, Nobili F, Robert P, Tsolaki M, Vellas B, Verhey F, Byrne EJ: Patient and caregiver perspectives of quality of life in dementia. An investigation of the relationship to behavioural and psychological symptoms in dementia. Dement Geriatr Cogn Disord 2008;26:138146.

14 Logsdon RG, Gibbins LE, McCurry SM, Teri L: Assessing quality of life in older adults with cognitive impairments. Psychosom Med 2002;64:510-519.

15 Bruvik FK, Ulstein ID, Ranhoff AH, Engedal K: The quality of life of people with dementia and their family carers. Dement Geriatr Cogn Disord 2012;34:7-14.

16 Nakanishi K, Hanihara T, Mutai H, Nakaaki S: Evaluating the quality of life of people with dementia in residential care facilities. Dement Geriatr Cogn Disord 2011;32:39-44.

17 Yeager CA, Hyer L: Apathy in dementia: relations with depression, functional competence, and quality of life. Psychol Rep 2008;102:718-722.

18 Ballard CG, Margallo-Lana ML: The relationship between antipsychotic treatment and quality of life for patients with dementia living in residential and nursing home care facilities. J Clin Psychiatry 2004;65:23-28.

19 van Vliet D, de Vugt ME, Bakker C, Pijnenburg YAL, Vernooij-Dassen MJFJ, Koopmans R, Verhey F: Time to diagnosis in young-onset dementia as compared with late-onset dementia. Psychol Med 2012;42:423-432.

20 van Vliet D, de Vugt ME, Bakker C, Koopmans RTCM, Verhey FRJ: Impact of early onset dementia on caregivers: a review. Int J Geriatr Psychiatry 2010;25:1091-1100.

21 Harris PB, Keady J: Selfhood in younger onset dementia: transitions and testimonies. Aging Ment Health 2009; 13:437-444.

22 Harris PB, Keady J: Living with early onset dementia: exploring the experience and developing evidence-based guidelines for practice. Alzheimers Care Q 2004;5:111-122.

23 Mulders AJMJ, Fick IWF, Bor H, Verhey FRJ, Zuidema SU, Koopmans RT: Prevalence and correlates of neuropsychiatric symptoms in nursing home patients with young-onset dementia: the BEYOnD study. J Am Med Dir Assoc 2016;17:495-500.

24 Mulders AJMJ, Zuidema SU, Verhey FR, Koopmans RT: Characteristics of institutionalized young onset dementia patients - the BEYOnD study. Int Psychogeriatr 2014;12:1973-1981.

25 Bakker C, de Vugt ME, van Vliet D, Verhey F, Pijnenburg YAL, Vernooij-Dassen MJFJ, Koopmans RT: Unmet needs and health-related quality of life in young-onset dementia. Am J Geriatr Psychiatry 2014;22:1121-1130.

26 Baptista MAT, Santos RL, Kimura N, Lacerda IB, Johannenssen A, Barca ML, Engedal K, Dourado MCN: Quality of life in young onset dementia: an updated systematic review. Trends Psychiatry Psychother 2016;38:6-13.

27 Ettema TP, Droes RM, de Lange J, Mellenbergh GJ, Ribbe MW: QUALIDEM: development and evaluation of a dementia specific quality of life instrument. Scalability, reliability and internal structure. Int J Geriatr Psychiatry 2007;22:549-556. 
Appelhof et al.: The Determinants of Quality of Life of Nursing Home Residents with Young-Onset Dementia and the Differences between Dementia Subtypes

28 Droes RM, Boelens-van der Knoop ECC, Bos J, Meihuizen L, Ettema TP, Gerrisen DL, Hoogeveen F, de Lange J, Scholzel-Dorenbos CJM: Quality of life in dementia in perspective. Dementia 2006;5:533-558.

29 Klapwijk MS, Caljouw MMA, Pieper MJC, van der Steen JT, Achterber WP: Characteristics associated with quality of life in long-term care residents with dementia: a cross-sectional study. Dement Geriatr Cogn Disord 2016;42:186-197.

30 American Psychiatric Association: Diagnostic and Statistical Manual of Mental Disorders-Text Revision: DSMIV-TR. Washington, American Psychiatric Association, 2000, vol 1, p 943.

31 Gorno-Tempini ML, Hillis AE, Weintraub S, Kertesz A, Mendez M, Cappa SF, Ogar JM, Rohrer JD, Black S, Boeve BF, Manes F, Dronkers NF, Vandenberghe R, Rascovsky K, Patterson K, Miller BL, Knopman DS, Hodges JR, Mesulam MM, Grossman M: Classification of primary progressive aphasia and its variants. Neurology 2011; 76:1006-1014.

32 McKeith IG: Consensus guidelines for the clinical and pathologic diagnosis of dementia with Lewy bodies (DLB): report of the consortium on DLB international workshop. J Alzheimers Dis 2006;9:417-423.

33 McKhann G, Drachman D, Folstein M, Katzman R, Price D, Stadlan EM: Clinical diagnosis of Alzheimer's disease: report of the NINCDS-ADRDA Work Group under the Auspices of Department of Health and Human Services task Force on Alzheimer's Disease. Neurology 1984;34:939-944.

34 Rascovsky K, Hodges JR, Knopman D, Mendez MF, et al: Sensitivity of revised diagnostic criteria for the behavioural variant of frontotemporal dementia. Brain 2011;134:2456-2477.

35 Roman GC, Tatemichi TK, Erkinjuntti T, Cummings JL, et al: Vascular dementia: diagnostic criteria for research studies. Report of the NINDS-AIREN international workshop. Neurology 1993;43:250-260.

36 Kat MG, de Jonghe JF, Aalten P, Kalisvaart CJ, Droes RM, Verhey FR: Neuropsychiatric symptoms of dementia: psychometric aspects of the Dutch neuropsychiatric inventory (NPI). Tijdschr Gerontol Geriatr 2002;33:150155.

37 Kaufer DI, Cummings JL, Ketchel P, Smith V, MacMillan A, Shelley T, Lopez OL, DeKosky ST: Validation of the NPI-Q, a brief clinical form of the neuropsychiatric inventory. J Neuropsychiatry Clin Neurosci 2000;12:233239.

38 Zuidema SU, de Jonghe JFM, Verhey FRJ, Koopmans RTCM: Neuropsychiatric symptoms in nursing home patients: factor structure invariance of the Dutch nursing home version of the neuropsychiatric inventory in different stages of dementia. Dement Geriatr Cogn Disord 2007;24:169-176.

39 Reisberg B, Ferris SH, de Leon MJ, Crook T: The global deterioration scale for assessment of primary degenerative dementia. Am J Psychiatry 1982;139:1136-1139.

40 WHO: Anatomical Therapeutic Chemical (ATC) Classification Index Including Defined Daily Doses (DDDS) for Plain Substances. Oslo, World Health Organisation Collaborating Centre for Drug Statistics Methodology, 1997.

41 Snijders TAB, Bosker RJ: Multilevel Analysis: An Introduction to Basic and Advanced Multilevel Modeling. London, Sage Publishers, 2012.

42 De Vugt ME, Riedijk SR, Aalten P, Tibben A, van Swieten JC, Verhey FRJ: Impact of behavioural problems on spousal caregivers: a comparison between Alzheimer's disease and frontotemporal dementia. Dement Geriatr Cogn Disord 2006;22:35-41.

43 Liu S, Jin Y, Shi Z, Huo YR, Guan Y, Liu M, Liu S, Ji Y: The effects of behavioral and psychological symptoms on caregiver burden in frontotemporal dementia, Lewy body dementia, and Alzheimer's disease: clinical experience in China. Aging Ment Health 2017;21:651-657.

44 van Vliet D, de Vugt ME, Kohler S, Aalten P, Bakker C, Pijnenburg YAL, Vernooij-Dassen MJFJ, Koopmans RTCM, Verhey FR: Awareness and its association with affective symptoms in young-onset and late-onset Alzheimer disease: a prospective study. Alzheimer Dis Assoc Disord 2013;27:265-271.

45 Perry RJ, Miller BL: Behavior and treatment in frontotemporal dementia. Neurology 2001;56:S46-S51. 